Jurnal Pilar Teknologi, Volume 3 Nomor 2 Edisi September 2018

ISSN Print : 2502-7042 ISSN Online : 2580-3557

http://pilar.unmermadiun.ac.id

\title{
Abu Ampas Tebu Pengurang Semen Dalam Paving
}

\author{
Kholiddien Tyas Jawara ${ }^{1}$, Pramudya Fathoni Winalda Purnama ${ }^{2}$, Olga Donny Prasetyo ${ }^{3}$, Tomi Tristono ${ }^{4}$ \\ ${ }^{1}$ Program Studi Teknik Sipil, Universitas Merdeka Madiun, Jl.Serayu No.79 Madiun \\ E-mail: kholiddientyasjawara@yahoo.com \\ ${ }^{2}$ Program Studi Teknik Sipil, Universitas Merdeka Madiun, Jl.Serayu No.79 Madiun \\ E-mail: pramodya.fathoni@gmail.com \\ ${ }^{3}$ Program Studi Teknik Sipil, Universitas Merdeka Madiun, Jl.Serayu No.79 Madiun \\ E-mail:olga.donny12@gmail.com \\ ${ }^{4}$ Program Studi D3 Manajemen Informatika, Universitas Merdeka Madiun, Jl.Serayu No.79 Madiun \\ E-mail:tomitristono@unmer-madiun.ac.id
}

\begin{abstract}
Cement is a basic requirement that is always needed in the construction work. Every year the price of cement has increased. In this experimental study using ash waste bagasse to reduce the amount of cement in paving by substituting it. Variations in the composition of the addition of bagasse ash are $0 \%, 5 \%, 10 \%, 15 \%, 20 \%, 25 \%$ of cement volume and with a ratio of $1: 4$, i.e., 1 cement and 4 sand. Based from the results of compressive strength analysis, water absorption, and density, the paving with a mixture of ash-bagasse gain of 5\% is the best when compared to other mixtures. The result are a compressive strength of 34.63 MPa, the water retention capacity of $2.12 \%$ and the density of $1.39 \mathrm{gr} / \mathrm{cm}^{3}$. The paving with a mixture of $10 \%$ bagasse ash yielded a compressive strength of $33.84 \mathrm{Mpa}$, the water retention capacity of $2.23 \%$ and the density of $1.37 \mathrm{~g} / \mathrm{cm}^{3}$, indicating that $10 \%$ ash addition had the same paving test results without the addition of ash bagasse. In SNI 03-0691-1996, paving with the addition of bagasse ash by $5 \%$ and 10\% including as the paving of quality $B$.
\end{abstract}

Keywords : ash of waste bagasse, paving, pozzolan.

\section{PENDAHULUAN}

Seiring berjalannya waktu harga semen di pasaran mengalami peningkatan yang cukup signifikan. Berbagai usaha untuk mensubsitusi pemakaian semen dengan bahan serupa yang lain pada sebuah bangunan konstruksi telah banyak diteliti. Hal ini tentu bermaksud agar dapat menekan/ mengurangi jumlah penggunaannya namun hasilnya tetap berkualifikasi baik.

Penelitian Karwur (2013) telah melakukan pencampuran semen dengan serbuk kaca. Campuran tersebut mempunyai kelebihan, diantaranya pada kuat tekan beton yang tinggi dengan penggunaan kaca sebesar $10 \%$. Namun campuran tersebut mempunyai kekurangan diantaranya yaitu bahan baku kaca itu sendiri ternyata sangat langka di lapangan dan limbah kaca juga harus melalui tahap penghancuran untuk di jadikan serbuk.
Penelitian ini menggunakan bahan pengurang semen yaitu limbah abu ampas tebu yang berasal dari pengolahan pabrik gula. Alasannya karena limbah abu ampas tebu bersifat pozzolan. Penggunaan semen dapat digantikan oleh penggunaan bahan lain yang bersifat pozzolan. Pozolan adalah bahan yang mengandung senyawa silika atau silika alumina dan alumina, dalam bentuk yang halus dan beserta dengan adanya air maka senyawa- senyawa tersebut akan bereaksi dengan kalsium hidroksida dan mempunyai sifat mengikat seperti semen. Pada suhu normal campuran tersebut akan membentuk senyawa kalsium hidrat yang bersifat hidraulis dan mempunyai angka kelarutan yang cukup rendah (Nurchasanah,2012).

Sejauh ini pemanfaatan limbah abu ampas tebu di Indonesia belum mengenal adanya metode untuk, sehingga limbah tersebut banyak terbuang dan mengakibatkan pencemaran terhadap lingkungan. Menurut Wibowo (2013), limbah abu ampas tebu yang dihasilkan dari produksi seluruh 
pabrik gula Indonesia berkisar antara $500.000-700.000$ ton/tahun.

Penelitian ini bertujuan untuk memanfaatkan limbah abu ampas tebu sebagai bahan campuran pembuatan paving agar dapat mengurangi penggunaan semen serta mempunyai kuat tekan yang sesuai dengan SNI 03-0691-1996. Metode variasi pencampuran abu ampas tebu terhadap semen diantaranya $5 \%$, $10 \%, 15 \%, 20 \%, 25 \%$. Berdasarkan uji yang dilakukan maka diperoleh variasi penambahan abu ampas tebu sebagai bahan penghemat semen yang optimal dengan kualifikasi masih sesuai dengan SNI 03-0691-1996. Kami juga mengulas bagaimana pengaruh penambahan ampas tebu dengan variasi $5 \%, 10 \%, 15 \%, 20 \%$ dan $25 \%$ terhadap kuat tekan dan penyerapan air paving dibandingkan dengan paving standar.

Adapun keunggulan hasil paving dibanding produk yang lain yaitu berkurangnya penggunaan semen sehingga dapat menekan biaya produksi.

Kami telah mempelajari beberapa penelitian terdahulu tentang bahan lain pengganti semen. Beberapa penelitian tersebut diantaranya adalah sebagai berikut ini. Kaolin adalah salah satu mineral tanah liat (lempung) dimana mengandung beberapa lapis aluminium silikat. Kaolin apabila mendapat perlakuan panas atau dibakar maka akan menghasilkan Metakaolin yang memiliki kandungan senyawa Silika dan Alumina. Oleh karena itu Metakaolin merupakan material yang potensial untuk pembuatan beton (Khatib, 2009). Limbah sekam padi berasal dari penggilingan padi dan memiliki kandungan silika yang cukup tinggi sehingga bila dicampurkan ke campuran beton maka akan memperbaiki karakteristiknya (Hidayat, 2011).

\section{METODE PENELITIAN}

Penelitian eksperimental ini menggunakan metode subtitusi untuk menggantikan semen dengan abu ampas tebu dengan variasi perlakuan diantaranya 5\%, 10\%, 15\%, 20\%, $25 \%$. Parameter terikat yang diukur dalam penelitian ini diantaranya adalah hasil kuat tekan, penyerapan air dan densitas. Pengujian uji ini dilakukan di laboratorium Teknik Sipil - Universitas Merdeka Madiun dengan spesifikasi pengujian yang sudah di tetapkan.

Peralatan yang akan digunakan dalam penelitian ini adalah Ayakan, Timbangan merk Radjin, Gelas ukur, Stopwatch, Oven merk Memmert, Jangka sorong, Mesin aduk (molen), dan mesin uji tekan merk Universal Testing Macine (UTM). Bahan yang digunakan adalah pasir, semen, abu ampas tebu, dan air. Tahapan penelitian dapat dilihat dalam Gambar 1.

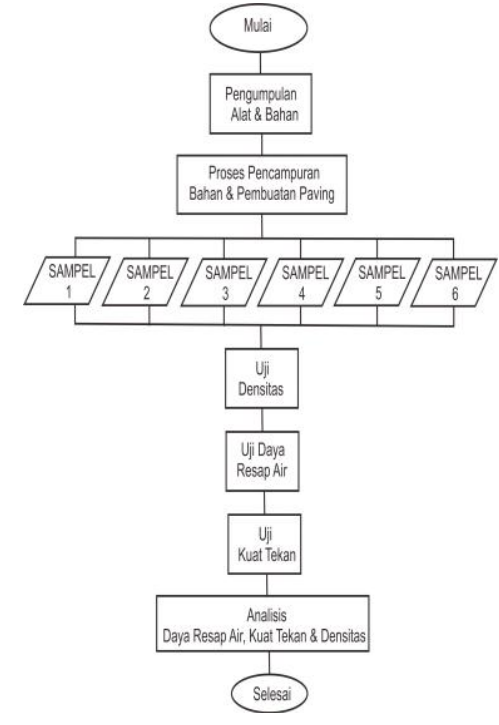

Gambar 1. Diagram alir pelaksanaan penelitian

\section{Proses Pembuatan}

Dalam penelitian ini di buat 24 (6 sampel x 4) buah benda uji dengan menggunakan cetakan segi enam ukuran diameter 23 dan $11,5 \mathrm{~cm}$. Rincian dalam pembuatan benda uji adalah sebagai berikut:

- Ayak pasir, kemudian beri air dengan jumlah sekitar $10 \%$ dari total pasir yang ada. Air berfungsi sebagai pelembab agar pasir tidak terlalu kering.

- Membuat mix design 6 jenis perlakuan dengan perbandingan 1:4 yaitu, 1 semen dan 4 pasir

- Setelah tercampur rata, masukkan dalam cetakan paving, kemudian press/ tekan menggunakan mesin hidrolik.

- Setelah semua proses tersebut selesai, tata secara berjajar paving tersebut di ruang dengan sirkulasi udara yang baik dan tunggu hingga 28 hari. Pada masa menunggu keadaan paving harus selalu dalam keadaan lembab. Oleh karena itu, harus dilakukan penyiraman di pagi dan sore hari.

\section{Proses Uji Kuat Tekan Paving}

Pada proses uji kuat tekan ini, dilakukan kegiatan-kegitan sebagai berikut :

- Mengukur dimensi benda uji.

- Meletakkan benda uji pada mesin uji tekan dengan arah penekanan sesuai dengan arah tekanan dalam pemakaian.

- Melakukan pembebanan hingga benda uji hancur.

- Mencatat beban maksimum yang dapat ditahan benda uji tersebut.

Adapan formula untuk menganalisis uji kuat tekan paving dengan cara Persamaan 1. Berikut ini

$$
f^{\prime} \mathrm{c}=\frac{P}{f}
$$

Dimana :

$\mathrm{f}^{\prime} \mathrm{c}=$ kuat tekan paving $(\mathrm{MPa})$

$\mathrm{P}=$ beban maksimum $(\mathrm{N})$

$\mathrm{f}=$ luas permukaan benda uji $\left(\mathrm{mm}^{2}\right)$ 


\section{Proses Uji Penyerapan Air Paving}

Pada proses uji ini, dilakukan kegiatan-kegitan sebagai berikut :

- Memasukkan benda uji dalam keadaan seutuhnya direndam dalam keadaan bersih suhu ruangan selama \pm 24 jam.

- Mengangkat benda uji dari air, dan air limbahnya dibiarkan meniris \pm 1 menit,

- Menyeka permukaan benda uji dengan kain untuk menghilangkan kelebihan air yang masih tertinggal.

- Menimbang benda uji.

- Benda uji di keringkan didalam oven dengan suhu $105^{\circ} \mathrm{C}$

- Menimbang benda uji kembali.

Formula untuk menganalisis penyerapan air paving dengan cara Persamaan 2. Berikut ini.

$$
\text { Penyerapan }=\frac{A-B}{B} \times 100 \%
$$

\section{Dimana :}

$\mathrm{A}=$ berat basah benda uji $(\mathrm{Kg})$

$\mathrm{B}=$ berat kering benda uji (setelah dioven $)(\mathrm{Kg})$

\section{Proses Uji Densitas Paving}

Proses ini menggunakan prinsip Archimides dengan menggunakan neraca digital. Kegiatan yang dilakukan dalam proses ini adalah:

- Sampel yang telah mengalami pengerasan, dikeringkan di dalam drying oven dengan suhu $(105 \pm 5)^{\circ} \mathrm{c}$, selama 1 jam.

- Kemudian timbang massa sampel kering (paving), $\mathrm{m}_{\mathrm{s}}$ dengan menggunakan neraca digital.

- Sampel yang telah ditimbamg, kemudian di rendam dalam air selama 1 jam yang bertujuan untuk mengoptimalkan penetrasi air terhadap sampel uji. Setelah itu, permukaan sampel dilap dengan kain flanel dan catat massa air setelah di rendam dalam air $m_{b}$

- Gantung sampel, pastikan dalam posisi tengah dan tidak menyentuh alas beker gelas yang berisi air, dimana masssa sampel berikut menggantung didalam air adalah $\mathrm{m}_{\mathrm{g}}$

- Terakhir sampel dilepas dari tali penggantung dan catat massanya $m_{k}$

- Dengan mengetahui besaran-besaran diatas, maka nilai densitas paving dapat ditentukan dengan menggunakan persamaan.

Metode untuk menganalisis densitas paving dengan cara Persamaan 3. Berikut ini.

$$
\begin{aligned}
& \mathrm{Ppc}=\frac{\mathrm{ms}}{\mathrm{mb}-(\mathrm{mg}-\mathrm{mk})} \times \mathrm{P} \text { air } \\
& \text { Dimana: } \\
& \mathrm{Ppc} \quad=\text { Densitas }\left(\mathrm{gr} / \mathrm{cm}^{3}\right) \\
& \mathrm{m}_{\mathrm{s}} \quad=\text { Massa sampel kering }(\mathrm{gr}) \\
& \mathrm{m}_{\mathrm{b}} \quad=\text { Massa sampel setelah direndam air }(\mathrm{gr}) \\
& \mathrm{m}_{\mathrm{g}} \quad=\text { Massa sampel digantung didalam air }(\mathrm{gr}) \\
& \mathrm{m}_{\mathrm{k}} \quad=\text { Massa kawat penggantung (gr) } \\
& \mathrm{P} \text { air }=\text { Densitas air }\left(1 \mathrm{gr} / \mathrm{cm}^{3}\right)
\end{aligned}
$$

\section{HASIL DAN PEMBAHASAN}

Hasil dari pengujian dan analisis paving berdasarkan parameter yang telah ditetapkan dapat dilihat dalam Tabel 1. Dan Ilustrasi hubungan varian penambahan abu ampas tebu terhadap kuat tekan, penyerapan air dan densitas dapat dilihat dalam Gambar 2, Gambar 3, dan Gambar 4 berikut ini.

Tabel 1. Hasil pengujian dan analisis paving

\begin{tabular}{ccccccccc}
\hline Perlakuan & Banding & PC $(\mathrm{Kg})$ & PS $(\mathrm{Kg})$ & Air $(\mathrm{Kg})$ & $\begin{array}{c}\text { Abu } \\
\text { Ampas } \\
\text { Tebu }(\mathrm{Kg})\end{array}$ & $\begin{array}{c}\text { Kuat Tekan } \\
(\mathrm{MPa})\end{array}$ & $\begin{array}{c}\text { Penyerapan } \\
\text { Air }(\%)\end{array}$ & $\begin{array}{c}\text { Densitas } \\
\left(\mathrm{gr} / \mathrm{cm}^{3}\right)\end{array}$ \\
\hline $0 \%$ & $1: 04$ & 1 & 4 & 0,5 & 0 & 33.52 & 2.18 & 1.36 \\
$5 \%$ & $1: 04$ & 0,95 & 4 & 0,5 & 0,05 & 34.63 & 2.12 & 1.39 \\
$10 \%$ & $1: 04$ & 0,9 & 4 & 0,5 & 0,10 & 33.84 & 2.17 & 1.37 \\
$15 \%$ & $1: 04$ & 0,85 & 4 & 0,5 & 0,15 & 31.45 & 2.23 & 1.33 \\
$20 \%$ & $1: 04$ & 0,8 & 4 & 0,5 & 0,20 & 30.41 & 2.28 & 1.3 \\
$25 \%$ & $1: 04$ & 0,75 & 4 & 0,5 & 0,25 & 29.14 & 2.31 & 1.26 \\
\hline
\end{tabular}

Dari tabel diatas maka pengaruh abu ampas tebu terhadap Kuat tekan, Penyerapan air, serta densitas paving dengan 6 perlakuan yang berbeda dapat digambarkan melalui grafik berikut ini. 


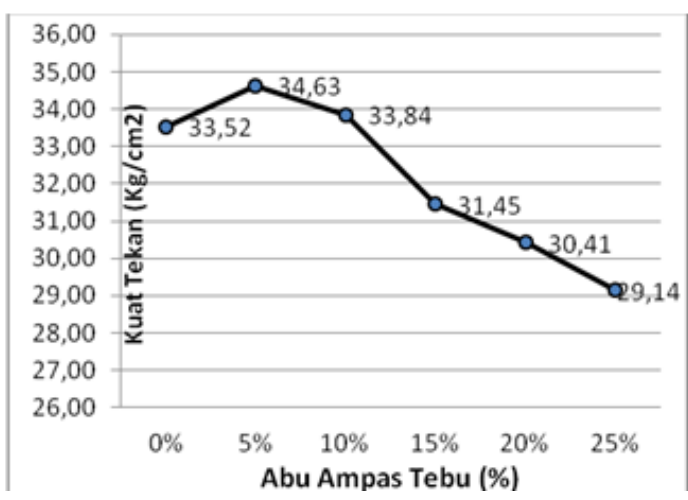

Gambar 2. Grafik hubungan varian penggantian semen dengan abu terhadap kuat tekan paving

Berdasarkan gambar 2 hasil pengujian kuat tekan didapatkan bahwa rata-rata kuat tekan yang terbaik ialah paving dengan varian penambahan abu ampas tebu sebesar 5\%. Dimana paving tersebut memiliki kuat tekan lebih tinggi daripada paving tanpa substitusi abu ampas tebu yaitu sebesar $34.63 \mathrm{Kg} / \mathrm{cm}^{2}$. Sedangkan varian $10 \%$ menunjukan kuat tekan hampir sama dengan paving tanpa abu ampas tebu yaitu sebesar $33,84 \mathrm{Kg} / \mathrm{cm}^{2}$. Untuk varian yang lebih besar $(15 \%$, $20 \%, 25 \%$ ) kuat tekan paving mengalami penurunan karena kandungan $\mathrm{SiO}_{2}$ dalam abu ampas tebu bereaksi dengan sisa kapur hasil pembebasan reaksi antara senyawa semen dan air sehingga membentuk $\mathrm{CaO} \mathrm{SiO}_{2}$ (Kalsium Silikat Hidrat) yang bersifat keras dan memiliki sifat kelarutan yang rendah. Jika jumlah $\mathrm{SiO}_{2}$ yang disubtitusikan semakin banyak, maka kekuatan paving juga bertambah. Namun hanya bertambah sampai titik optimumnya kemudian menurun. Varian $15 \%$, $20 \%$, 25\% telah melewati batas optimum sehingga menunjukan hasil yang menurun. Dilihat dari hasil pengujian didapatkan hasil paving yang

termasuk memenuhi syarat paving mutu B menurut SNI 03-0691-1996 yaitu paving dengan kuat tekan rata-rata 20 $\mathrm{Kg} / \mathrm{cm}^{2}$, minimal kuat tekan $17 \mathrm{Kg} / \mathrm{cm}^{2}$ dan penyerapan ratarata $6 \%$

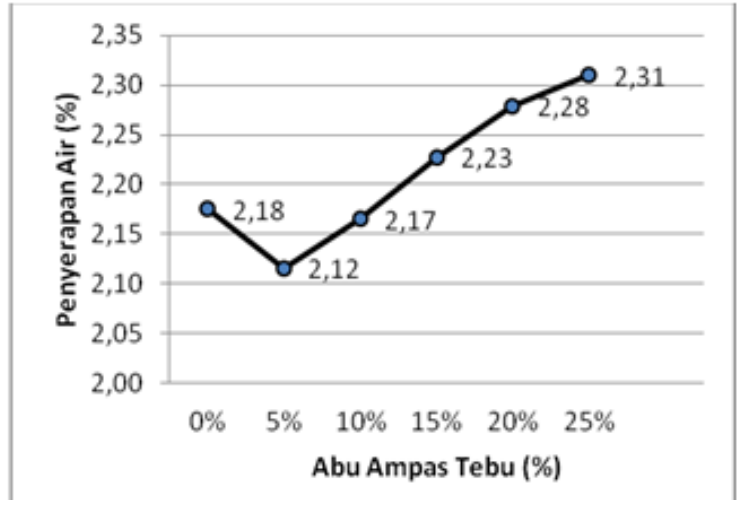

Gambar 3. Grafik hubungan varian penggantian semen dengan abu terhadap penyerapan air paving

Dari Gambar 3 hasil pengujian penyerapan air dapat dilihat bahwa semakin banyak presentase penambahan abu ampas tebu maka semakin tinggi pula penyerapan air yang terjadi. Butiran abu ampas tebu yang lebih kecil membuat paving jauh lebih padat, hal ini dikarenakan abu ampas tebu dapat mengisi pori-pori paving yang ada.

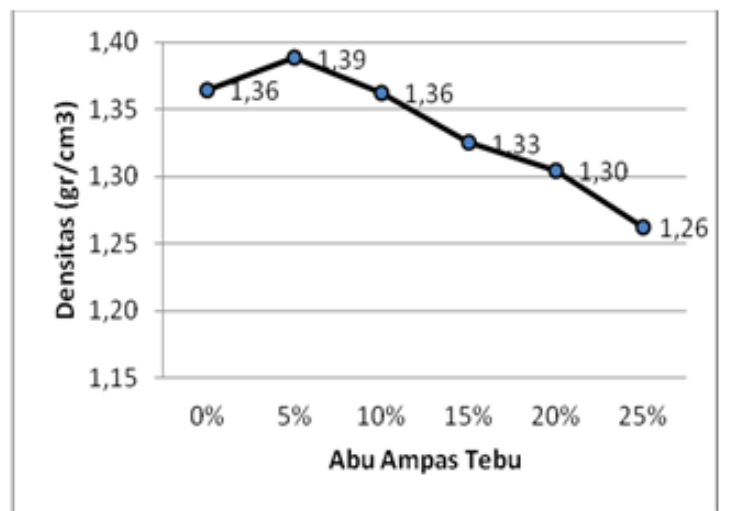

Gambar 4. Grafik hubungan varian penggantian semen dengan abu terhadap penyerapan air paving

Dari Gambar 4 hasil pengujian densitas menunjukan bahwa semakin besar prsentasi penggantian abu ampas tebu terhadap semen maka nilai densitasnya semakin kecil. Hal ini dikarenakan jumlah semakin banyak jumlah abu ampas tebu yang dimasukan, kekuatan dari matrial juga bertambah sampai titik optimumnya dan kemudian akan mengalami penurunan. kekuatan paving dapat bertambah karena rongga-rongga pada paving terisi dan mengalami penurunan akibat prosentasi abu yang lebih banyak pengakibatkan pengikatan semen kurang sempurna. Pada penambahan abu ampas tebu sebesar 5\% menunjukan titik optimal dan varian $10 \%, 15 \%, 20 \%, 25 \%$ menunjukan penurunan

\section{KESIMPULAN}

Berdasar dari hasil analisis kuat tekan, daya resap air, serta densitas, paving dengan campuran penambahan abu ampas tebu sebesar 5\% adalah yang tebaik dibandingkan dengan campuran yang lain. Dengan kuat tekan sebesar 34,63 Mpa, Daya resap air sebesar 2,12 \% Serta Densitas sebesar 1.39 $\mathrm{gr} / \mathrm{cm} 3$. Paving dengan campuran penambahan abu ampas tebu sebesar $10 \%$ didapatkan hasil kuat tekan sebesar 33.84 Mpa, Daya resap air sebesar $2.23 \%$ serta Densitas sebesar $1.37 \mathrm{gr} / \mathrm{cm} 3$, hal ini menunjukan bahwa penambahan abu $10 \%$ memiliki hasil uji paving yang sama sengan tanpa penambahan abu ampas tebu.

Pada penambahan abu ampas tebu $15 \%$ sampai $25 \%$ kualitas paving menurun di bandingkan dengan paving tanpa penambahan abu ampas tebu. Dalam SNI 03-0691-1996 paving dengan penambahan abu ampas tebu sebesar 5\% dan $10 \%$ ini termasuk klasifikasi paving kualitas B.

\section{DAFTAR PUSTAKA}

Firdaus, M. R., 2013. Pengaruh Penambahan Serbuk Batu Bata Sebagai Bahan Campuran Beton Ditinjau Terhadap Uji Kuat Tekan Beton. Fakultas Teknik Universitas Malang. 
Karwur, H.Y . 2013. Kuat Tekan Beton Dengan Bahan Tambah Serbuk Kaca Sebagai Substitusi Parsial Semen. 1 (4): 278-281.

Kurniawan, T. (2015). Penambahan Abu Terbang Terhadap Kuat Tekan Paving. Fakultas Teknik Universitas Merdeka madiun

Nurchasana, Y., Renaningsih dan Listyawan A. B., 2012. Pemanfaatan Pozzolan Alam Sebagai Bahan Baku Dalam Rekayasa Teknologi Beton di Kabupaten Pacitan. 1 (4): 3-6.

Siregar, N. (2010). Fly ash dan bottom ash ampas tebu. Fakultas Teknik Universitas Sumatra Utara.

SNI 03-0691-1996. 1996. Bata Beton (Paving Block). Badan Standarisasi Nasional. Jakarta.

SNI 15-2049-2004. 2004. Semen Portland. Badan Standarisasi Nasional. Jakarta.

SNI 03-6805-2002. 2002. Metode Pengujian untuk mengukur nilai kuat tekan Beton pada umur awal dan memproyeksikan kekuatan pada umur berikutnya. Badan Standarisasi Nasional. Jakarta.

Wibowo, R. G., 2012. Penambahan Abu Ampas Tebu Terhadap Kuat Tekan Batako. Fakultas Teknik Universitas Merdeka Madiun.

Hidayat, A. (2011). Pengaruh penambahan abu sekam padi terhadap kuat tekan beton $K-225$.

Khatib, J.M. (2009). Low Temperature Curing of Metakaolin Concrete. Journal of Materials in Civil Engineering, ASCE, Vol. 21, No. 8, pp. 362-367. 